\title{
Effect of deflector curvature on hydrodynamic performances of a double-slotted cambered otter-board
}

\author{
Lei $W A N G^{1}$, Lu Min $W A N G^{1}$, Jian Gao SHI ${ }^{1}$, Wen Wen $Y U^{1}$, Guang Rui $Q I^{1}$, Xun ZHANG ${ }^{1, *}$, Rong Jun ZHANG ${ }^{2}$, and Tian \\ Shu $Z H A N G^{2}$ \\ ${ }^{1}$ Key Laboratory of Oceanic and Polar Fisheries, Ministry of Agriculture; East China Sea Fisheries Research Institute, Chinese Academy \\ of Fishery Sciences, Shanghai 200090, China \\ ${ }^{2}$ China National Fisheries Corporation, Beijing 100032, China
}

\begin{abstract}
The effect of deflector curvature on hydrodynamic performances of a double-slotted cambered otter-board was investigated using engineering models in a wind tunnel. Four different curvature $(0.06,0.09$, 0.12 and 0.15 ) were evaluated at a wind speed of $28 \mathrm{~m} / \mathrm{s}$. Parameters measured included: drag coefficient $\mathrm{C}_{\mathrm{x}}$, lift coefficient $C_{y}$, pitch moment coefficient $C_{m}$, center of pressure coefficient $C_{p}$, over a range of angle of attack $\left(0^{\circ}\right.$ to $\left.70^{\circ}\right)$. These coefficients were used in analyzing the differences in the performance among the four otter-board models. Results showed that the maximum lift coefficient $\mathrm{C}_{\mathrm{y}}$ of the otter-board model with the curvature (0.06) of two deflectors was highest $\left(2.020\right.$ at $\left.\alpha=55^{\circ}\right)$. The maximum $C_{y} / C_{x}$ of the otter-board with the curvature $(0.12)$ of two deflectors was highest $\left(3.655\right.$ at $\alpha=22.5^{\circ}$ ). A comparative analysis of $\mathrm{C}_{\mathrm{m}}$ and $C_{p}$ showed that the stability of otter-board model with the curvature $(0.12)$ of two deflectors is better in pitch, and the stability of otter-board model with the curvature $(0.06)$ of two deflectors is better in roll. The findings of this study can offer useful reference data for the structural optimization of otter-boards for trawling.
\end{abstract}

\section{Introduction}

Otter-boards are an important part of fishing gear for spreading the trawl mouth. The merits of the hydrodynamic performance of otter-boards can be measured on the basis of the lift coefficient of the otterboard, the drag coefficient of the otter-board, and the pitching moment coefficient of the otter-board [1]. Optimizing the structure of otter-boards may improve the hydrodynamic performance of the otter-board [2-3]. Extensive studies on the hydrodynamic performance of otter-boards have been conducted in the United States, Japan, Norway, and other countries [4-8]. In China, researchers have studied the relevant hydrodynamic performance of otter-boards since the early 1980s, including the hydrodynamic performance and optimization of different otter-boards with various structure types [9-13]. Improvements in the hydrodynamic performance of otter-boards has become a major research interest as the development of offshore trawler fleets increasing globally in recent decades. Some studies have shown that the slit in otter-boards can reduce the resistance and improve the stability of otterboards [14-19]. The following study investigates the importance of the curvature of the deflector within the otter-board. We describe an experiment using otterboard models ( $\mathrm{n}=4$ designs) in a wind tunnel in which we measured various hydrodynamic coefficients for a range of angles of attack. The results are relevant as a reference for the study of the structural parameters of the deflector curvature of otter-boards.

\section{Material and Methods}

\subsection{Design and manufacture of otter-board model}

The otter-boards evaluated in this study were doubleslotted curved structures comprising two deflectors and a main-panel (figure 1). This structure design was based on the used bottom trawl otter-board currently, and was simplified in order to meet objectives and requirements of the study. Only the curvature of two deflectors was modified.

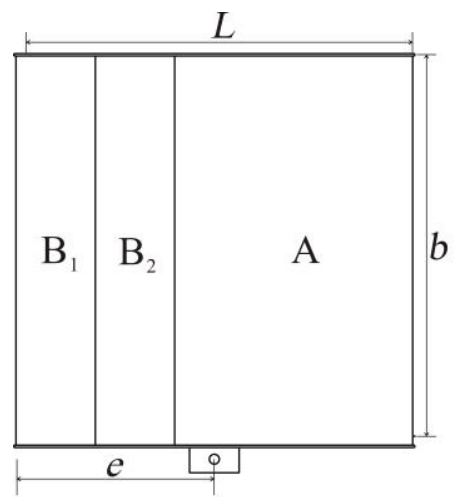

Front view

\footnotetext{
* Corresponding author: zhangxun007@hotmail.com
} 


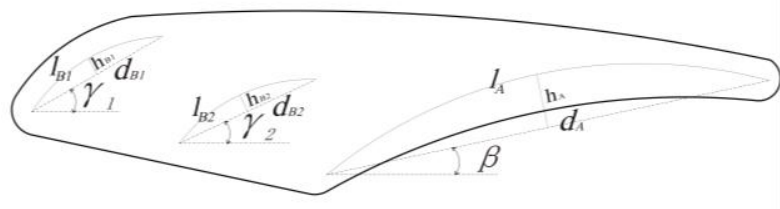

Top view

Fig. 1. Structure and parameters of otter-board Note: L: chord; b: span; e: distance between fulcrum and the front end of model; $B_{1}, B_{2}$ : deflector; A: main-panel; $\gamma_{1}, \gamma_{2}$ : angle of deflector; $\beta$ : angle of main-panel; $1_{\mathrm{B} 1}, 1_{\mathrm{B} 2}$ : arc length of deflector; $1_{A}$ : arc length of main-panel; $h_{B}, h_{B}, h_{A}$ : distance from the vertex of the arc to the arc chord; $d_{B 1}, d_{B} 2, d_{A}$ : length of arc chord.

Each of models had an aspect ratio of 1.0, surface area of $0.25 \mathrm{~m}^{2}$, and were identical in many structural parameters and dimensions (table 1). The curvature of the main-panel was $12 \%$ and was consistent in all models. The only parameter that varied between the models was the curvature of two deflectors $\left(\delta_{B 1}, \delta_{B 2}\right)$. The models are made of steel with painted surfaces (figure 2).

Table 1. Descriptive characteristics of the four model otter boards evaluated in this study.

\begin{tabular}{|c|c|c|c|c|}
\hline No. & $\mathbf{1}$ & $\mathbf{2}$ & $\mathbf{3}$ & $\mathbf{4}$ \\
\hline $\boldsymbol{L} / \mathbf{m}$ & 0.5 & 0.5 & 0.5 & 0.5 \\
\hline $\boldsymbol{b} / \mathbf{m}$ & 0.5 & 0.5 & 0.5 & 0.5 \\
\hline $\boldsymbol{\lambda}$ & 1 & 1 & 1 & 1 \\
\hline $\boldsymbol{S} / \mathbf{m}^{\mathbf{2}}$ & 0.25 & 0.25 & 0.25 & 0.25 \\
\hline $\boldsymbol{e} / \mathbf{m}$ & 0.25 & 0.25 & 0.25 & 0.25 \\
\hline $\boldsymbol{\gamma}_{\boldsymbol{1}}$ & $30^{\circ}$ & $30^{\circ}$ & $30^{\circ}$ & $30^{\circ}$ \\
\hline $\boldsymbol{\gamma}_{\boldsymbol{2}}$ & $25^{\circ}$ & $25^{\circ}$ & $25^{\circ}$ & $25^{\circ}$ \\
\hline $\boldsymbol{\beta}$ & $6^{\circ}$ & $6^{\circ}$ & $6^{\circ}$ & $6^{\circ}$ \\
\hline $\boldsymbol{l}_{\boldsymbol{B} \boldsymbol{1}}$ & 0.127 & 0.127 & 0.127 & 0.127 \\
\hline $\boldsymbol{l}_{\boldsymbol{B} \boldsymbol{2}}$ & 0.12 & 0.12 & 0.12 & 0.12 \\
\hline $\boldsymbol{l}_{\boldsymbol{A}}$ & 0.313 & 0.313 & 0.313 & 0.313 \\
\hline $\boldsymbol{\delta}_{\boldsymbol{B} \boldsymbol{1}}$ & 0.06 & 0.09 & 0.12 & 0.15 \\
\hline $\boldsymbol{\delta}_{\boldsymbol{B} \boldsymbol{2}}$ & 0.06 & 0.09 & 0.12 & 0.15 \\
\hline $\boldsymbol{\delta}_{\boldsymbol{A}}$ & 0.12 & 0.12 & 0.12 & 0.12 \\
\hline
\end{tabular}

Note: $L$ : chord; $b$ : span; $\lambda(b / L)$ : aspect ratio; $S(L \cdot b)$ : surface area; $e$ : distance between fulcrum and the front end of model; $\gamma_{1}, \gamma_{2}$ : angle of deflector; $\beta$ : angle of main-panel; $l_{B 1}, l_{B 2}$ : arc length of deflector; $l_{A}$ : arc length of main-panel; $\delta_{B I}\left(h_{B I} / d_{B I}\right)$, $\delta_{B 2}\left(h_{B 2} / d_{B 2}\right)$ : curvature of deflector; $\delta_{A}\left(h_{A} / d_{A}\right)$ : curvature of main-panel.
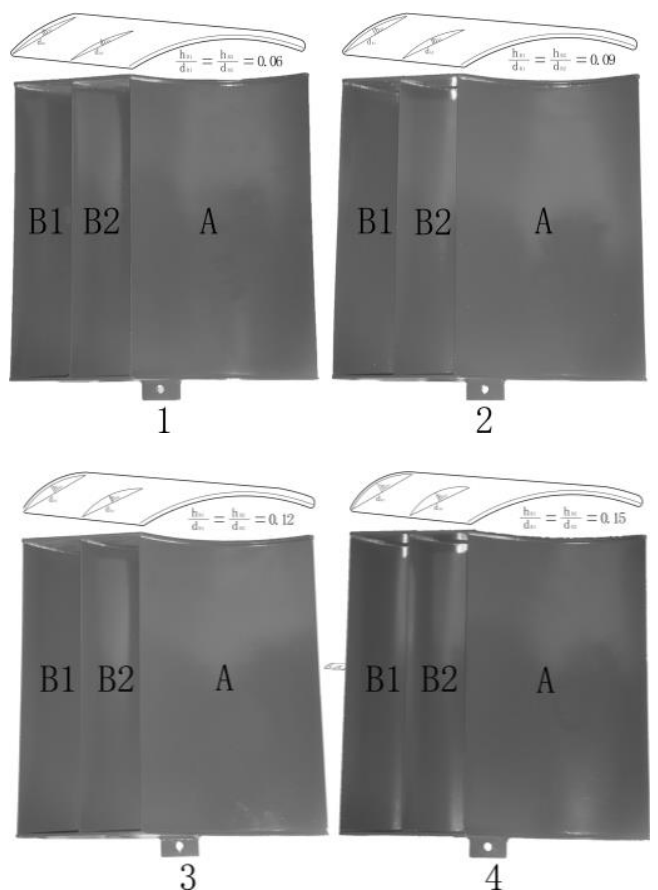

Fig. 2. Four otter-board models evaluated in this study. Note: A: main-panel; $\mathrm{B}_{1}, \mathrm{~B}_{2}$ : deflector.

\subsection{Test facility}

The wind tunnel used for this experiment was the NH-2 wind tunnel located at Nanjing University of Aeronautics and Astronautics, China. The tunnel is a closed reflux wind tunnel with a double-string test section. The experiment was conducted in a small test section. Dimensions of the test section were $6 \mathrm{~m}$ (length) $\times 3 \mathrm{~m}$ (width) $\times 2.5 \mathrm{~m}$ (height). The cross-sectional area was $7.18 \mathrm{~m}^{2}$. The minimum and maximum wind speeds of the tunnel were $5 \mathrm{~m} / \mathrm{s}$ and $90 \mathrm{~m} / \mathrm{s}$, respectively. Figure 3 illustrates the experimental setup inside the wind tunnel. The otter-board models were attached to a dynamometer compromising a six-component mechanical tower-balance to measure forces in all directions. The data acquisition and processing system used is composed of a pre -amplifier and a four networked computer system.

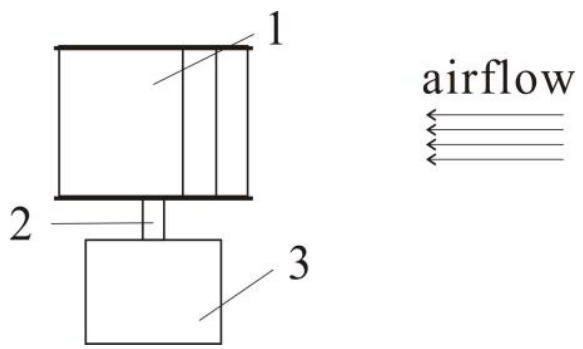

Fig. 3. Installation instruction of otter-board model in wind tunnel.

Note: 1.otter-board model 2.model connection 3.six-component force balance

\subsection{Test method}

2.3.1 Parameter definition of test model 
Test model need to be installed on the wind tunnel in six-component balance mechanical base according to the order, angle of attack of model rotates by the $0^{\circ}-70^{\circ}$ when the wind speed reaches $28 \mathrm{~m} / \mathrm{s}$ (room temperature $20{ }^{\circ} \mathrm{C}$ ), wherein the angle of attack in the range $0^{\circ}-50^{\circ}$, $2.5^{\circ}$ intervals to record a measurement data point, after the attack angle $50^{\circ}$, each measurement interval of $5^{\circ}$ to record data points, there are 25 sets of data totally, including the drag coefficient $C_{x}$, the lift coefficient $C_{y}$, the pitch moment coefficient $C_{\mathrm{m}}$ and the center of pressure coefficient $C_{\mathrm{p}}$.

The relevant parameters of models in the wind tunnel test section are defined as shown in figure 4. In figure 4, $\mathrm{O}$ is torque reference point, which is the punch of the model at the bottom. During the test, the resistance of the model is provided by the force of balance along the $\mathrm{X}$ axis direction, the lift is provided by the force of balance along the Z-axis direction, and the pitch moment is provided by the $M_{\mathrm{y}}$ of balance along the $\mathrm{Z}$-axis direction.

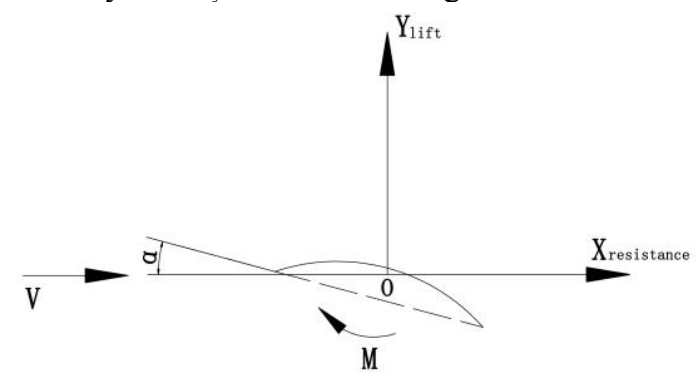

Fig. 4. Parameter definition diagram of test model in wind tunnel.

For this test, Wind speed $V=28 \mathrm{~m} / \mathrm{s}$, when the Reynolds number $R_{e}=V L / v=0.93 \times 10^{6}$ (coefficient of viscosity $\left.v=15 \times 10^{6} \mathrm{~m}^{2} \cdot \mathrm{s}^{-1}\right)[14]$.

\subsubsection{Parameter definition of test measurement}

Three components: lift $Y$, drag $X$, pitching moment $M$ (around the fulcrum), while the distance from the center of pressure to the front-end otter-board $d=e-(M / N)$ [16], ( $N$ is the normal force).

Lift coefficient

$$
C_{y}=\frac{Y}{\rho V^{2} S / 2} \quad[3] ; \quad \text { drag }
$$

coefficient $\quad C_{x}=\frac{X}{\rho V^{2} S / 2} \quad ; \quad$ pitch moment coefficient $\quad C_{m}=\frac{M}{\rho V^{2} S L / 2} \quad ; \quad$ center of pressure coefficient $C_{p}=\frac{d}{L}$.

Air density $\rho=1.225 \mathrm{~kg} / \mathrm{m}^{3}$ in above formula; $S$ is otter-board area $\left(\mathrm{m}^{2}\right) ; L$ is the otter-board chord length (m).

All the experimental data have been carried out the stent disturbance correction which is completed by the method of taking out light pole directly.

\section{Results and Discussion}

\subsection{Drag coefficient and lift coefficient}

Data from the experiment included the drag coefficient $C_{x}$, the lift coefficient $C_{y}$, the pitch moment coefficient $C_{\mathrm{m}}$, and the center of pressure coefficient $C_{p}$. The liftdrag ratio was computed $\left(C_{y} / C_{x}\right)$, which is an important factor for determining the merits of the hydrodynamic performance of otter-boards. An otter-board with excellent hydrodynamic properties can achieve higher lift-drag ratio and improved stability; such performance can be analyzed by comparing the pitching moment coefficient $C_{\mathrm{m}}$ stencil and the center of pressure coefficient $C_{p}$. The test data were divided into groups, yielding $C_{x}-\alpha, C_{y}-\alpha$ and $C_{y} / C_{x}-\alpha$ graphs shown in figure 5 . These graphs are used for analyzing the differences in the hydrodynamic properties of the four otter-board models.
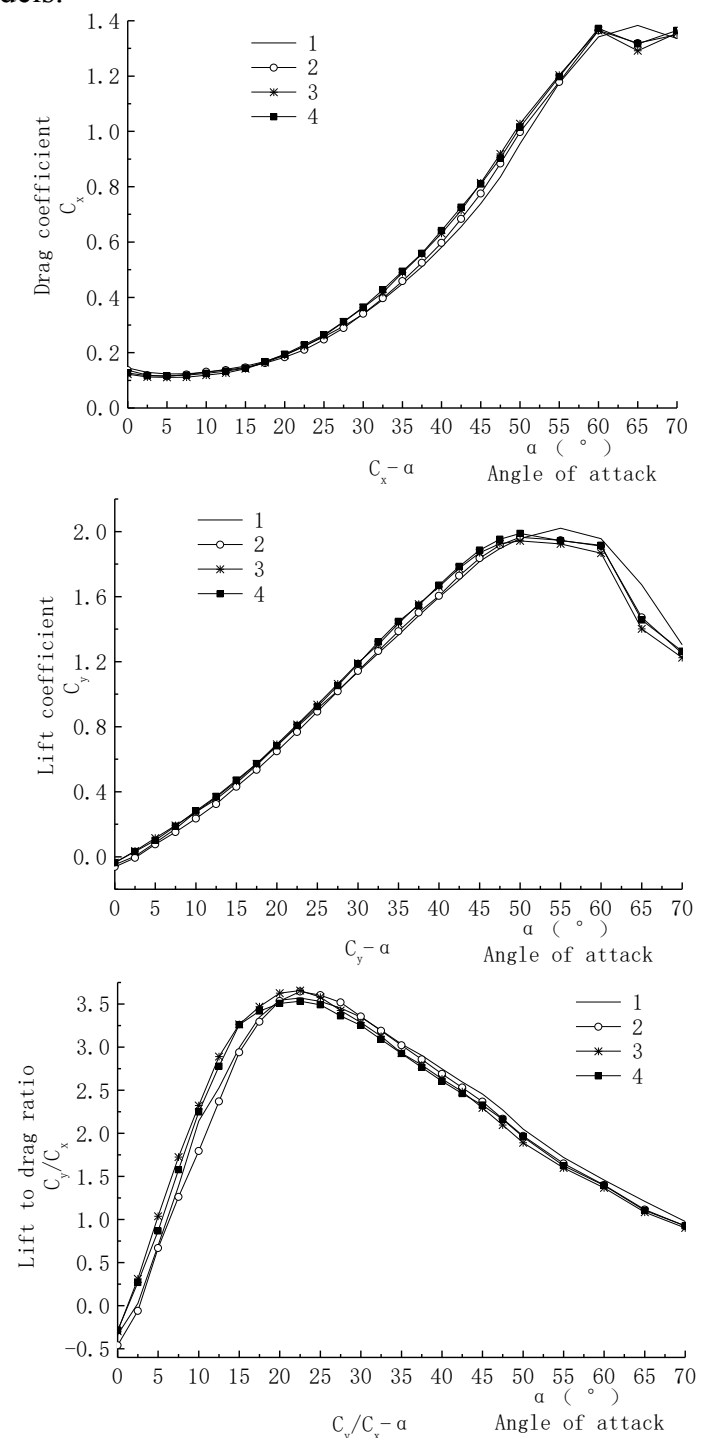

Fig. 5. Hydrodynamic properties of four otter-board models across a range of angle of attack.

In figure 5, $C_{x}-\alpha$ and $C_{y}-\alpha$ graphs show the variation curve of the drag and lift coefficient of the four models while the angle of attack $\alpha$ changes. The maximum lift coefficients $C_{y}$ of No. 1, No. 2, No. 3, and No. 4 otterboard models were $2.020\left(\alpha=55^{\circ}\right), 1.965\left(\alpha=50^{\circ}\right)$, $1.942\left(\alpha=50^{\circ}\right)$, and $1.988\left(\alpha=50^{\circ}\right)$, respectively. It shows that the maximum lift coefficient of No.1 model with the deflector curvature 0.06 is largest. 


\subsection{Lift-drag ratio}

In figure 5, the maximum lift-drag ratios of No.3 model with the deflector curvature 0.12 , there is $3.655(\alpha=$ $\left.22.5^{\circ}\right)$. The maximum lift-drag ratios of No. 1 , No. 2 and No. 4 models are $3.571\left(\alpha=22.5^{\circ}\right), 3.644(\alpha=$ $\left.22.5^{\circ}\right)$ and $3.534\left(\alpha=22.5^{\circ}\right)$, respectively. The higher or lower curvature of defectors may result in a lower maximum lift-drag ratio.

\subsection{Stability of otter-board}

Pitching moment can be divided into upper and lower pitching moments, which are usually distinguished by positive and negative values, Positive means the otterboard tilts backward, and negative means tilts forward. Its absolute value represents the level of pitching moment; and the pitching moment coefficient tending to 0 represents the more excellent stability of otter-board. In practice, comparing the absolute value $C_{m}$ corresponding to the operation angle of attack of otterboard may determine the stability level of otter-board. For comparison, the angle of attack corresponding to the maximum lift-drag ratio $C_{\mathrm{y}} / C_{\mathrm{x}}$ is selected [20]. The corresponding absolute value of $C_{m}$ is shown in table 2 . The absolute value of $C_{m}$ of No. 3 model is 0.144 , so hence, the stability of No. 3 otter-board model is better in pitch.

Table 2. Parameters of four otter-board models for stability analysis.

\begin{tabular}{|c|c|c|c|}
\hline No. & $\begin{array}{c}\text { Angle } \\
\text { corresponding to } \\
\text { the maximum lift } \\
-\mathbf{d r a g} \text { ratio } \\
\boldsymbol{\alpha}\end{array}$ & $\left|\boldsymbol{C}_{\mathbf{m}}\right|$ & $\begin{array}{c}\text { Variable } \\
\text { coefficient of } \\
\boldsymbol{C}_{\mathbf{p}}\end{array}$ \\
\hline 1 & $22.5^{\circ}$ & 0.183 & $6.83 \%$ \\
\hline 2 & $22.5^{\circ}$ & 0.163 & $7.85 \%$ \\
\hline 3 & $22.5^{\circ}$ & 0.144 & $8.13 \%$ \\
\hline 4 & $22.5^{\circ}$ & 0.160 & $7.81 \%$ \\
\hline
\end{tabular}

The stability in roll of otter-board can be measured according to the center of pressure coefficient $C_{\mathrm{p}}$; and the way of comparison is analyzing the coefficient of variation in $C_{\mathrm{p}}$ within the range of angle approximately $5^{\circ}$ of the angle of attack corresponding to the maximum lift-drag ratio; a smaller coefficient results in the improved stability [21]. The calculated data are shown in table 2. The minimum variation coefficient of $C_{\mathrm{p}}$ is $6.83 \%$; this value also means that the stability of No. 1 otter-board model is better in roll of otter-board.

\section{Conclusion}

Test analysis shows that the curvature of two deflectors has a point for equilibrating the hydrodynamic performances of otter-board. No.3 otter-board with the deflector curvature of 0.12 has the higher maximum liftdrag ratio at the angle of attack $22.5^{\circ}$, and at this angle of attack, the lift coefficient $(0.813)$ is also higher than the other three models. In the meanwhile, the stability of No.3 otter-board model in pitch is also better comparatively, and the stability of No.1 otter-board model in roll is better. The data and conclusions of this study can provide a reference for the design of otterboard.

\section{Acknowledgements}

This work is financially supported by the National Key Technology R\&D Program (No. 2013BAD13B04).

\section{References}

1. G. X. Guo, T. Y. Liu, X. H. Huang, F. L. Gu. Theory and Practice of trawl doors Kinetic. Guang. Sci. \& Tech. Pub. (2008)

2. Y. Q. Zhou. Mechanics of fishing gear. Chi. Agr. Pub. (2001)

3. X. Z. Chen, X. C. Huang. Theory and method of gear model test. Sh. Sci. \& Tech. Pub. (2011)

4. A. Sala, J. Prat, J. Antonijuan, A. Lucchetti. Fis. Res. 156, 100(2009)

5. Y. Takahashi, Y. Fujimori, F. X. Hu, X. L. Shen, N. Kimura. Fis. Res. 400, 161(2015)

6. M. K. Broadhurst, D. J. Sterling, R. B. Millar. Fis. Man. \& Eco. 407, 22(2015)

7. K. Fukuda, F. X. Hu, T. Tokai, K. Matuda. Ni. Su. Gak. 97, 66(2000)

8. C. D. Park, K. Matuda, F. X. Hu. Ni. Su. Gak. 920, 62(1996)

9. X. L. Shen, F. X. Hu, T. Kumazawa, D. Shiode, T. Tokai. Fis. Sci. 433, 81(2015)

10. L. Wang, L. M. Wang, C. L. Feng, A. Z. Zhou, W. W. Yu, Y. Zhang, X. Zhang. Aqu. \& Fis. 234, 2(2017)

11. L. Wang, L. M. Wang, J. G. Shi, Y. Zhang, Y. L. Liu, W. W. Yu, X. Zhang. MAT. W. Con. 5004, 128(2017)

12. L. Wang, L. M. Wang, A. Z. Zhou, J. G. Shi, Y. Zhang, G. D. Xu, X. Zhang. MAT. W. Con. 5003, 128(2017)

13. L. Wang, L. M. Wang, C. L. Feng, X. Zhang, A. Z. Zhou, Y. Zhang, Y. L. Liu, G. R. Qi. Mar. Fis. 682, 39(2017)

14. X. Zhang, J. H. Wang, M. Y. Wang, Y. F. Yu, B. S. Xu. Jou. Fis. Sci. Ch. 5, 11(2004)

15. J. H. Wang, M. Y. Wang, X. Zhang, Y. F. Yu, B. S. Xu. Jou. Fis. Sci. Ch. 9, S1(2004)

16. M. Y. Wang, J. H. Wang, X. Zhang, Y. F. Yu, B. S. Xu. Jou. Fis. Ch. 311, 3(2004)

17. C. C. Li, Z. L. Liang, L. Y. Huang, W. F. Zhou, P. Sun, L. Wang. Mar. Sci. 69, 11(2013)

18. L. Wang, L. M. Wang, C. L. Feng, X. Zhang, J. G. Shi, Y. Zhang, Y. L. Liu, W. W. Yu. Fis. Mod. 55, 6(2015) 
19. L. Wang, L. M. Wang, W. W. Yu, C. L. Feng, J. G. Shi, Y. L. Liu, X. Zhang. Con. In. For. En. Sus. De. 530, 75(2016)

20. L. Yang. Fis. Sci. Tec. 38, 2(1996)

21. L. Yang. Fis. Sci. Tec. 42, 5(1996) 